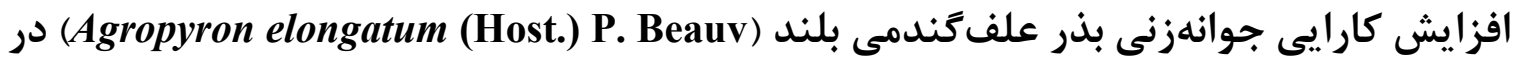
شرايط تنشهاى دماى پايين و خشكى با استفاده از اسمويرايمينتَ اوره

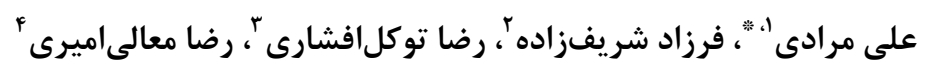

'استاديار كروه زراعت و اصلاح نباتات دانشكاه ياسوج

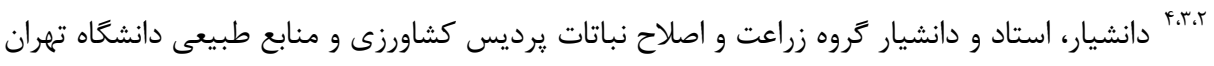

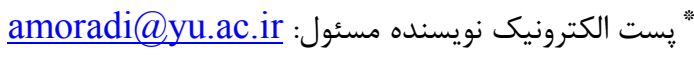

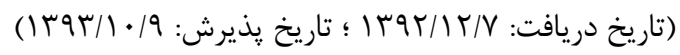

جكيده

يرايمينَ بذر از جمله راههاى افزايش كارايى جوانهزنى بذر در شرايط تنشى زنده و غيرزنده مىباشد. بدين

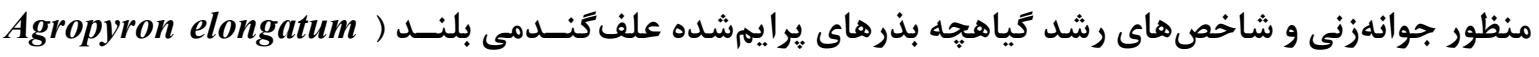

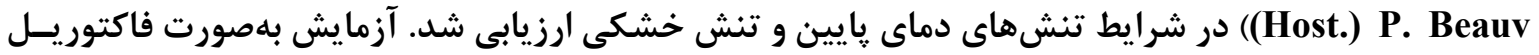
سه عاملى در قالب طرح بلوكهاى كامل تصادفى با جهار تكرار اجرا شد. عاملهاى آزمايشى شامل يرايمينــى

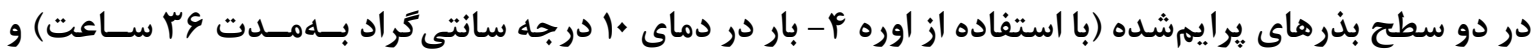

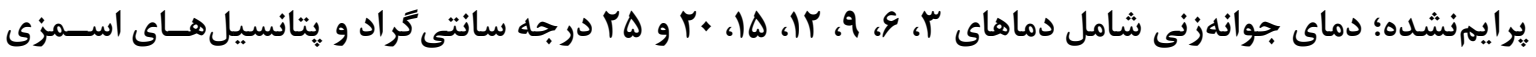

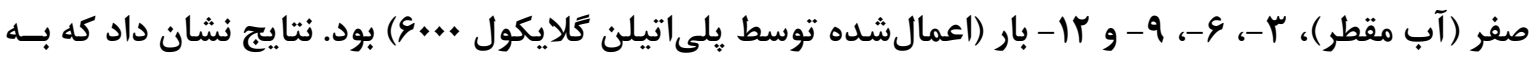

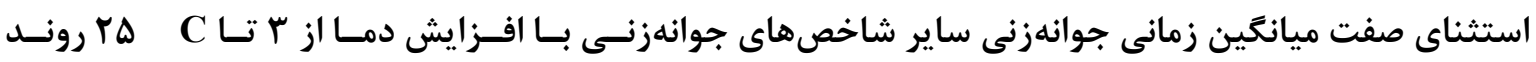

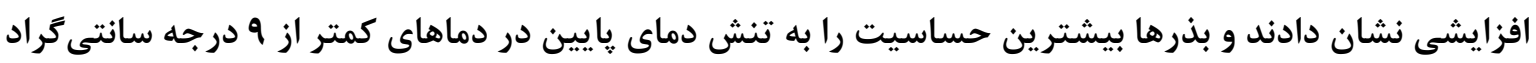

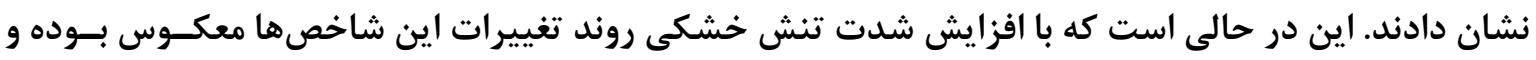

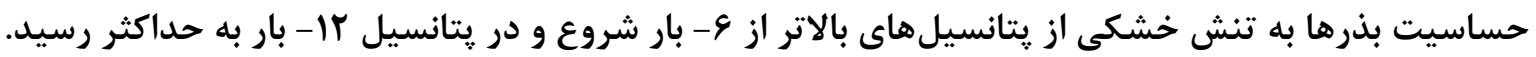

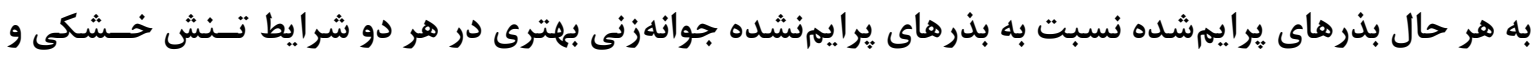

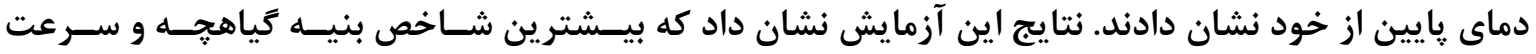

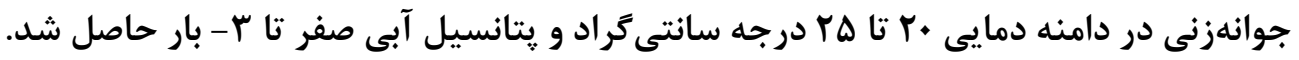
وازههاى كليدى: اسمويرايمينَ بذر، يتانسيل آبى، دماى يايين، علفَّندمى بلند

مقدمه

مى جندساله و يايا هستند و بيشتر آنها از نظر توليد علوفه سبز و خشك داراى اهميت فراوانى هستند. اين خياهان اكثراً بهصورت خالص و يا كشت مخلوط با ساير زياهان

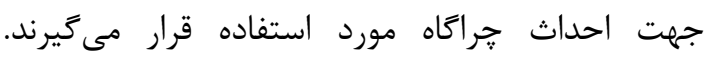
بهعلاوه برخى از گَونههاى آن به علت يوشانيدن سطح

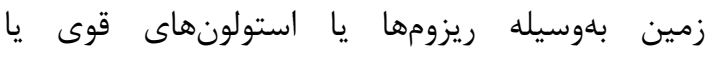

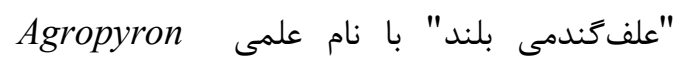
elongatum (Host.) P. Beauv علفگَندمى شور و علفگندمى خوشهاى از خانواده يواسه' بوده و اغلب در مناطق معتدله بهصورت خالص و يا كشت مخلوط با ساير كياهان مورد استفاده قرار

\footnotetext{
${ }^{1}$ Poaceae
} 
مثبت يرايمينَ بر كاهش اثرات منفى تنشهاى خشكى

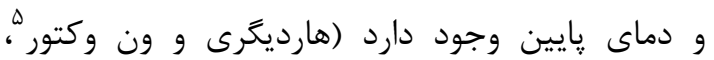

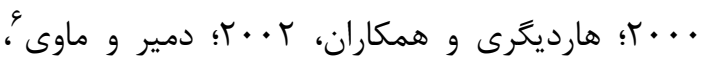

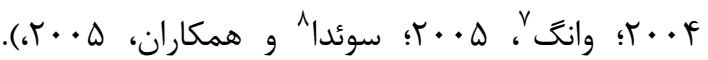
افزايش سرعت جوانهزنى و استقرار بذر در مزرعه مىتواند منجر به افزايش توان كياهجه در جذب آب آب و عناصر

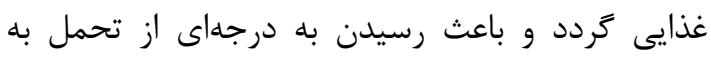

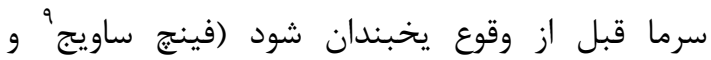

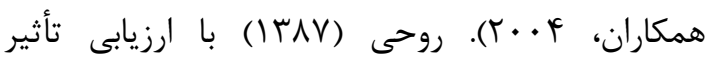

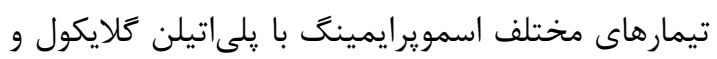

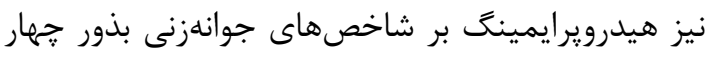
كراس مرتعى شامل Festuca arundinacea، g Bromus inermis ، Agropyron elongatum Festuca ovina

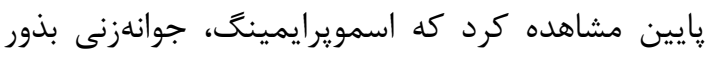

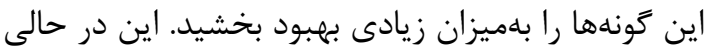

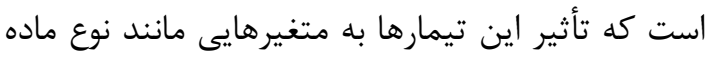

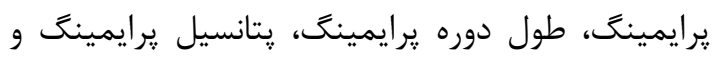

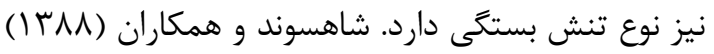

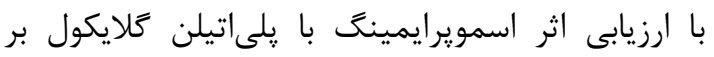

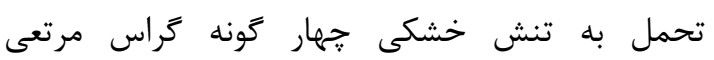
'Bromus inermis ‘Agropyron desertorum Secale montanum, Lolium prenne

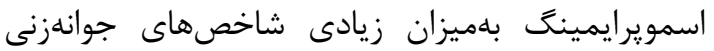
اين كونهها را در شرايط تنش خشكى بنى بهبود دادي داد و

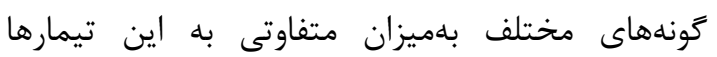
واكنش نشان دادند.

در مجموع شواهد نشان مىدهد در طى يرايمينَ

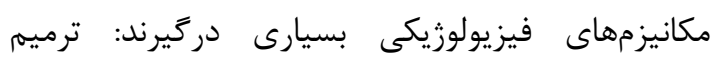

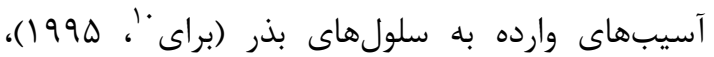
بيشرفت وقايع متابوليكى كه در مرحله دوم جذب آب آب آبل

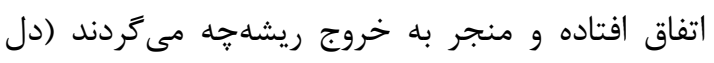

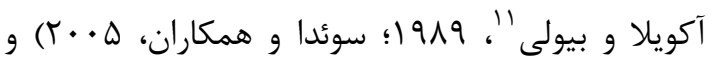

\footnotetext{
${ }^{5}$ Hardegree and Van vactor

${ }^{6}$ Demir and Mavi

${ }^{7}$ Wang

${ }^{8}$ Soeda

${ }^{9}$ Finch Savage

${ }^{10}$ Bray

${ }^{11}$ Dell Aquila and Bewley
}

جمنىشدن جهت جلوگيرى از فرسايش كشت مىشوند (كريمى، وعسا). در اين مناطق تحمل به تنش سرما و يخبندان ييشنياز بقاء گياهان در زمستان و شروع رشد

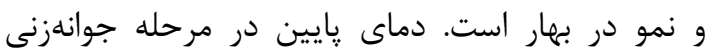

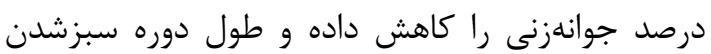

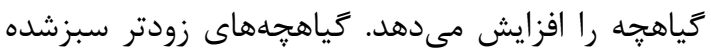
داراى قدرت رقابتى بالاترى در جوامع زياهى بوده و روني شانس بقاى بيشترى دارند (يسميك' و و همكاران، . ( . . )

دسترســى ضــعيف بـــه آب در منــاطق خــشك و

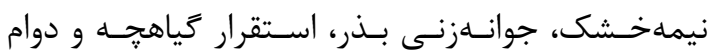
كراسهاى جندساله را شديداً محسـدود مـى كنـد. كـاهش

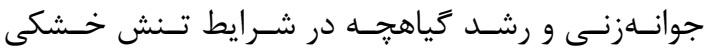
مىتواند نتيجه يكسرى از فر آيندهايى بيوشميايى مانند

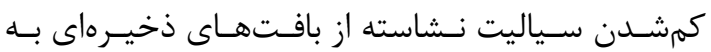

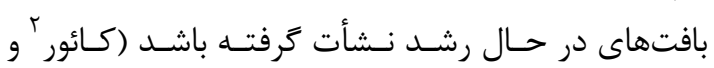

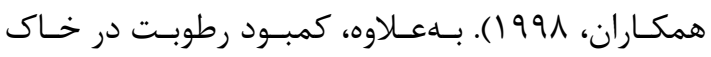
مىتواند جوانهزنى بـــر را از طريـق اثـرات اسـمزى كـهـ موجب تأخير در آبنوشى بذر يا طولانى شدن مرحله بله دوم

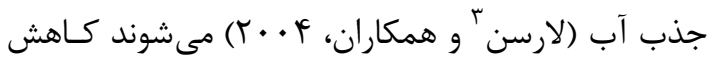

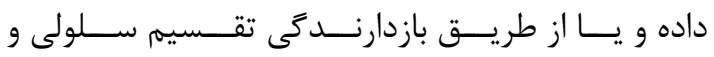
طويلشدن سلول، رشد ريشه تجه و ساقهجـهـ و در نهايـت

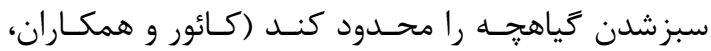

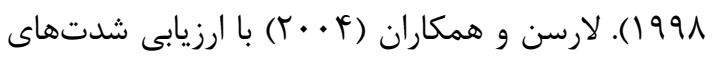

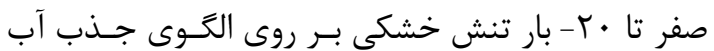
جهار گراس مرتعى، مشاهده نمودند كه ميزان آب جذب بـ

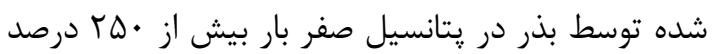

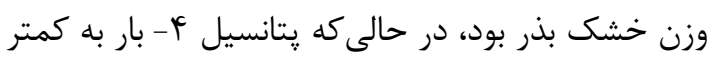

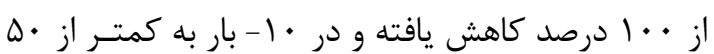
درصد نيز رسيد. وقتى بذور در خاى كشت مىشوند، مدت زمان

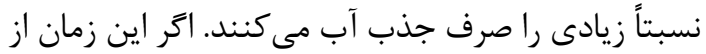
طريق : برايمكردن كاهش يابد، جوانهزنى سريعتر انجام

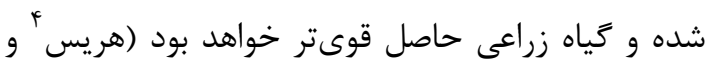

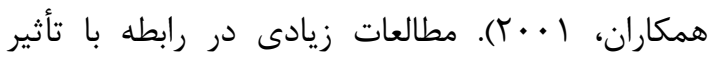

\footnotetext{
${ }^{1}$ Posmyk

${ }^{2}$ Kaur

${ }^{3}$ Larsen

${ }^{4}$ Harris
} 
در اين فرمول \%: يتانسيل اسمزى بر حسب بار؛ R: عدد ثابت كازها؛ i : ضريب ثابت يونيزاسيون ماده حل شونده (براى اوره ())T دماى محلول (درجه كلوين) و m: غلظت مولى ماده حلشده است.

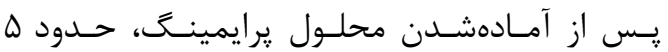
ميلىليتر از محلول اسمزى اوره عأ- بار به يترىديشهاى

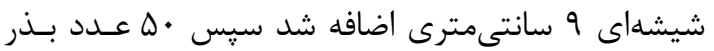
سالم بلهورت تصادفى انتخاب و در هر يترى قرار كرفت اين كار در هجهار تكرار • •ه بذرى براى هر كدام از تيمارها

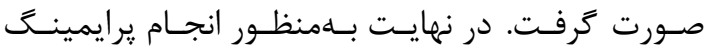
يترىها در شـرايط تـاريكى در داخـل زرمينـاتور (مـــل

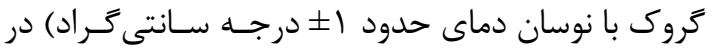

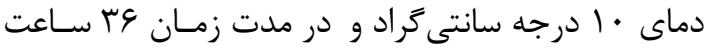

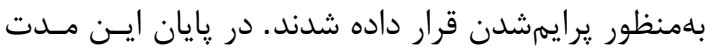

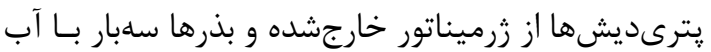

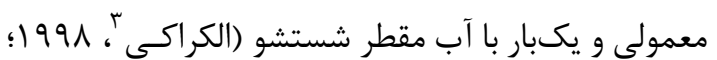

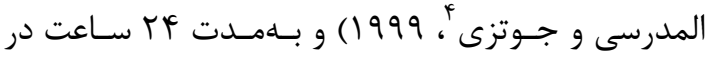

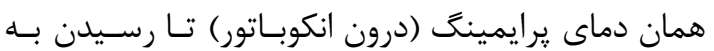

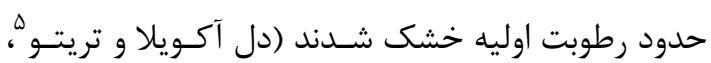

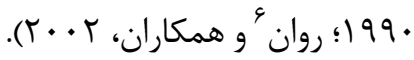

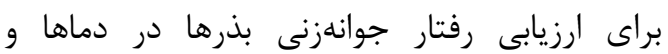
يتانسيلهاى آبى مختلف، ابتدا ه ميلىليتر آب مقطر آبرائر (يتانسيل صفر بار) يا محلول يلىاتيلن كلايكول

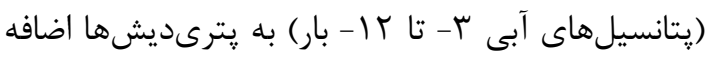

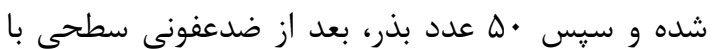
سوسيانسيون r در هزار قارجكش ويتاواكس، بلصورت تصادفى در داخل هر يترى قرار گرفت. يس إز كاشت

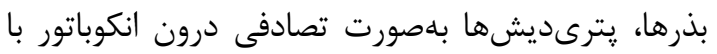

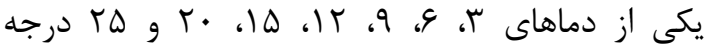
سانتى

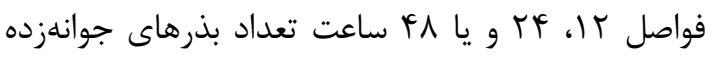
شمارششده و ثبت شدند. بذرها هنكامى جوانهزده فرض ترأ

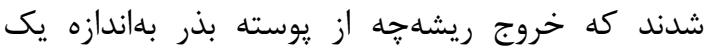

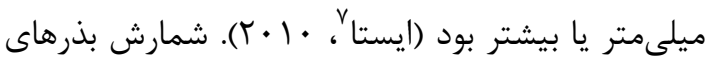

\footnotetext{
${ }^{3}$ Alkaraki

${ }^{4}$ Ał Mudarsi and Jutzi

${ }^{5}$ Dell'Aquila and Tritto

${ }^{6}$ Ruan

${ }^{7}$ ISTA
}

وقايعى مثل تسهيم بهتر آندوسيرم و مواد ذخيرهاى كه إنه

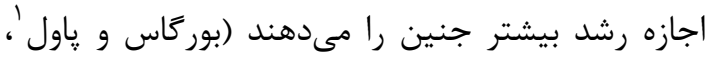
19194) ممكن است در طى يرايمينَ بذر اتفاق بيفتند

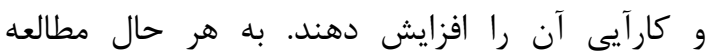
واكنشهاى مطلوب بذر با استفاده از روشهاى برايمينَ

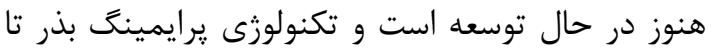
بهبود و اصلاح كامل آن ادامه مىيابد. همعام با افزايش

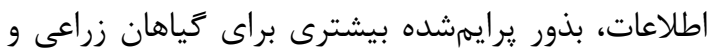

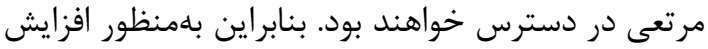
فهمم ما از اثرات مثبت يرايمكردن بذور، بلهويزه

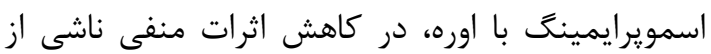

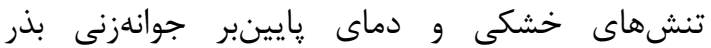
علفَندمى بلند تحقيق حاضر طراحى گرديد.

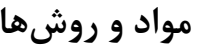

بلمنظور بررسى اثر تنشهاى خشكى و دماى پـايين بر جوانهزنى و شاخصهاى كياهجهاى بذرهاى يرايم شده

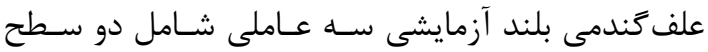

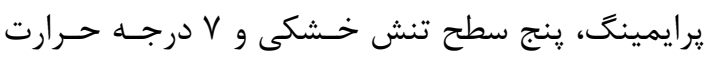

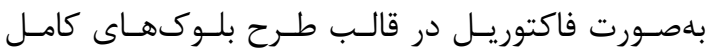
تصادفى با جهار تكرار در آزمايسشعاه علـوم و تكنولـوزى دات

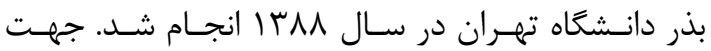
افزايش دقت اعمال تيمارها و ارزيابى مناسب شاخصهـان

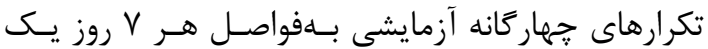

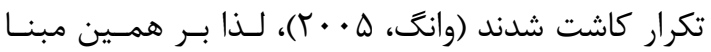

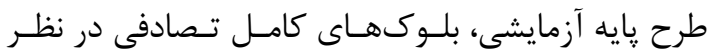

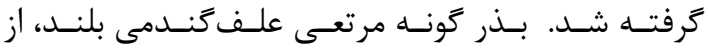

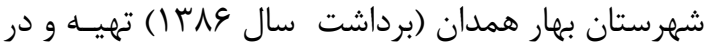
اين آزمايش مورد استفاده قرار كرفت. يتانسيلهاى مختلف يلى اتيلن كلايكول مورد استفاده

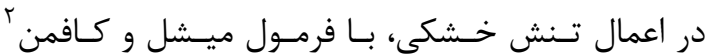

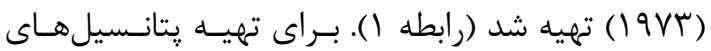
مختلف اوره نيز از رابطه وانهوف (رابطه () استفاده شد (ردائه

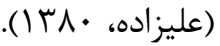

$$
\psi_{\mathrm{s}}=\mathrm{miRT}
$$

رابطه ا:

\footnotetext{
${ }^{1}$ Burgass and Powell

${ }^{2}$ Michel and Kaufman
} 


\section{نتايج و بحث درصد جوانهزنى}

نتايج جدول تجزيه واريانس دادههاى صفات مورد بررسى در گياه علفگَندمى بلند بيانكر آن است كه متغيرهاى تنش خشكى، تنش دمايى و ورايمينى بلهميزان معنىدارى صفت درصد جوانهزنى كل را تحت

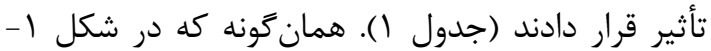
الف نيز مشخص است بذرهاى جوانهزده در دماى برائ

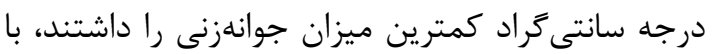
افزايش دما از ب به 9 درجه سانتى كراد، جوانهزنى كل كل

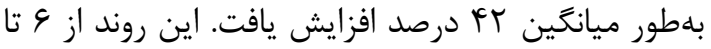
ها درجه سانتى كراد تغيير محسوسى نكرده و با افزايش

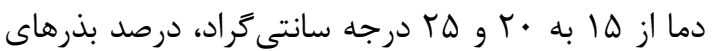
جوانهزه با شيب زيادى كاهش يافت. در اين شرايط شيب كاهش جوانهزنى براى بذرهاى يرايم شده آهستهتر از بذرهاى برايمنشده بود. بنابر اظهارات مير و و همكاران بران

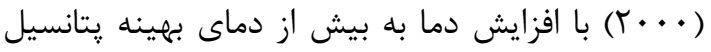

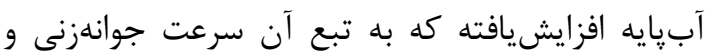
درصد جوانهزنى نهايى نيز كاهش مى يابد. با در نظر كرفتن معنى دارى اثـر متقابـل دمـاءتــنش

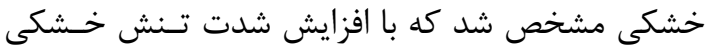

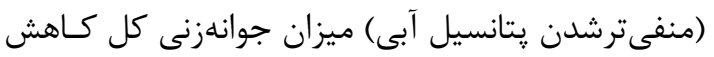
جشمعيرى نمود (شكل ا-ب). اين كـاهش در دماهـاى

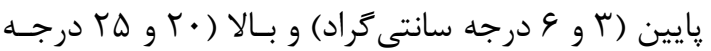

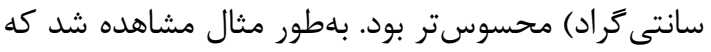

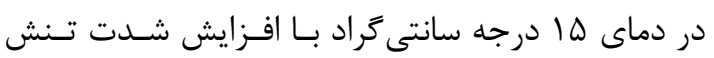

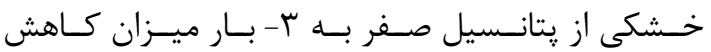
جوانهزنى الr درصد بود، اين در حالى اسـت كـهـ ميـزان

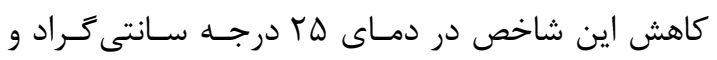
شدت تنش خشكى مشابه سٓ درصد بود. بهعبارت ديخـر

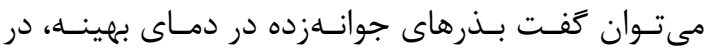

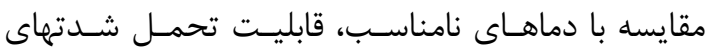

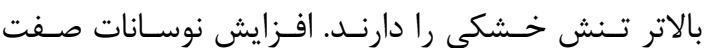
درصد جوانهزنى نهايى با كاهش يتانسيل آبى در جـاودار

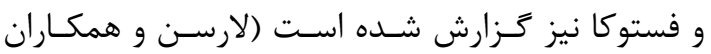
(Y.. Y

\footnotetext{
${ }^{6}$ Meyer
}

جوانهزده تا ال ب روز پِ از شروع آزمايش ادامه يافت. در

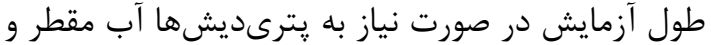
يا محلول يلىاتيلن كلايكول اضافه شد. صفات مورد

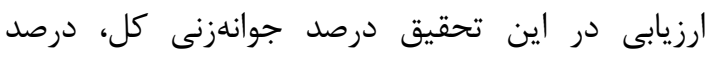
كياهجههاى غير عادى، سرعت جوانهزنى، ميانكَين زمان جوانهزنى، طول ريشه קه، طول ساقهجه، طول كياهجه، نسبت طول ريشه קه به ساقهجه و شاخص بنيه كَياهحه بودند. عدم يكنواختى واريانسهاى درصد جوانهزنى باعث شد كه، براى دادههاى اين صفت از تبديل زاويهاى (استفاده شد (المدرسى و جوتزى، (Arc sinX)

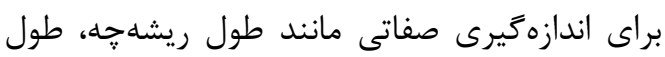
ساقهجه و طول كياهجه پِ إن از اتمام آزمايش از هر يترى تعداد • ا ع كياهجه بهصورت تصادفى انتخاب و اين صفات ثبت شد. ميانغين زمان جوانهزنى (MGT

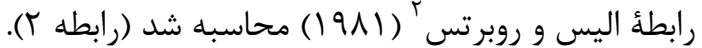

$$
\text { رGT= رابطه r }
$$

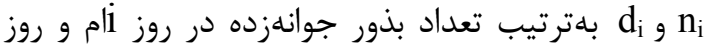

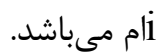
شاخص بنيه كياهجه (SVI') نيز از حاصل ضرب طول كياهجه (سانتىمتر) در درصد جوانهزنى بهدست

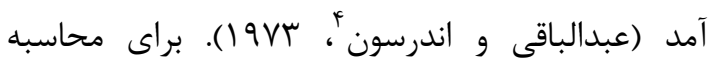

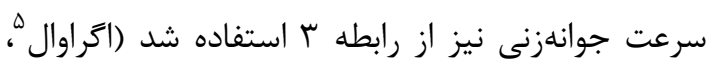

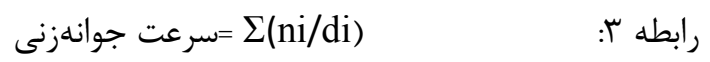

: تعداد بذرهاى جوانه زده در روز أlم و di تعداد روز يس از شروع آزمايش مى باشد.

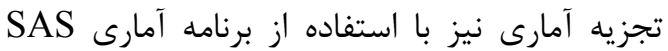

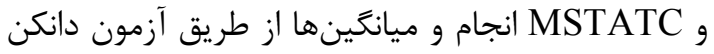
در سطح احتمال ه درصد مقايسه شدند.

\footnotetext{
${ }^{1}$ Mean Germination Time

${ }^{2}$ Ellis and Roberts

${ }^{3}$ Seedling Vigour Index

${ }^{4}$ Abdual-baki and Anderson

${ }^{5}$ Agrawal
} 
شدتهاى بالاتر تـنش خـشكى (يتانسيلهــاى 9-و و 9-

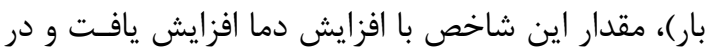

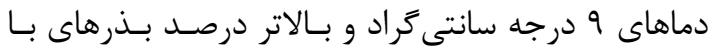

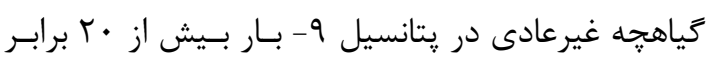

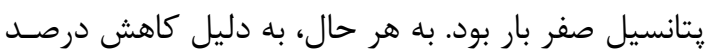

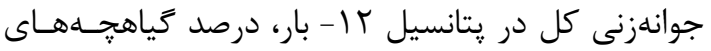

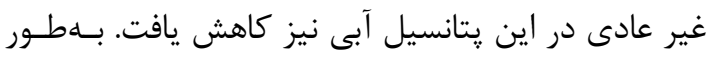

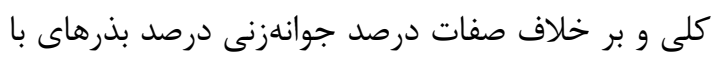

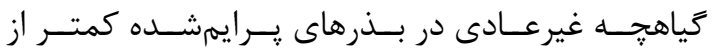

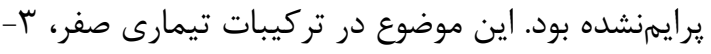

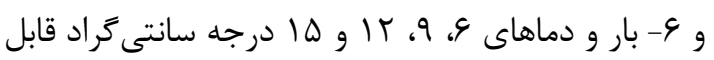

مشاهده است.
درصد گياهجههاى غيرعادى

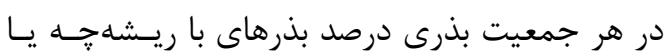

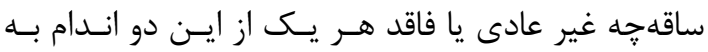

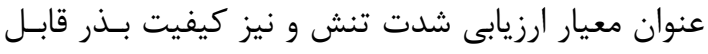
استفاده هستند. نتايج نشان داد كـه در ميـان تركيبـات مختلف تيمارى بيشترين درصد كياهجههاى غير عـادى ندان

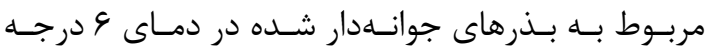

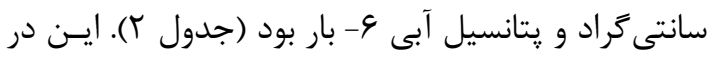
حالى است كه در دماى ها الدرجه سانتى كراد و يتانسيل صفر بار كمترين ميزان جوانهزنى غير عادى مشاهده شد.

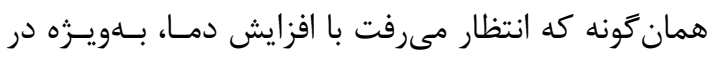

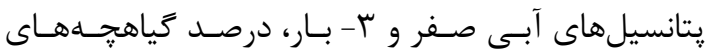

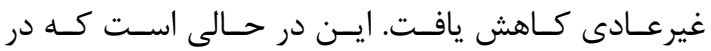

جدول ا- تجزيه واريانس صفات جوانهزنى و رشد كياهجه بذرهاى يرايمشده و يرايمنشده علفَندمى بلند در شرايط دمايى و پِانسيل آبى مختلف

\begin{tabular}{|c|c|c|c|c|c|c|c|c|}
\hline \multicolumn{7}{|c|}{ ميانگَين مربعات (MS) } & \multirow[b]{2}{*}{ آزادى } & \multirow[b]{2}{*}{ منبع تغييرات } \\
\hline شياخص & 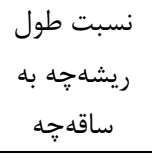 & كياهجه & ميانگين & جوانهزنى & غوانهزنى درصد & جوانهزنى درصد & & \\
\hline$r \Lambda^{\mathrm{ns}}$ & $\cdot / \cdot r^{\mathrm{ns}}$ & $\cdot / \Delta r^{\mathrm{ns}}$ & $\cdot / 4 \Delta^{\mathrm{ns}}$ & $|/ D|^{\mathrm{ns}}$ & $\Lambda^{\mathrm{ns}}$ & $10 \cdot{ }^{\mathrm{ns}}$ & r & تكرار \\
\hline$q q v^{* * *}$ & $9 / 0^{\text {*ै* }}$ & VGY": & Frr & $q 4 r^{* * * 0}$ & $r \Delta \Lambda \cdot{ }^{* * * *}$ & $\checkmark \vee \Delta \cdot{ }^{* * *}$ & 4 & دما \\
\hline $1 r v^{* * *}$ & 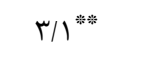 & $r v^{* *: *}$ & $r \Lambda^{* * * *}$ & 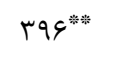 & $f \varphi^{\mathrm{ns}}$ & $r 109^{* * * *}$ & 1 & يرايمينگ \\
\hline $11 r q .{ }^{* * * *}$ & $T r / \Lambda^{* * * *}$ & $149 V^{* * *}$ & $|Y|^{\text {***** }}$ & $1099^{* * *}$ & 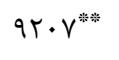 & 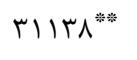 & r & تنش خشكى \\
\hline $1 \Delta \mathrm{V}^{\text {***m}}$ & $1 / \cdot 9^{\text {क** }}$ & $\Delta / \Upsilon^{* * * *}$ & $1 \cdot /^{* * * *}$ & $r r^{* * * *}$ & $14 q^{* * * *}$ & $\Delta V|\Delta|^{*}$ & 4 & دما×يرايمينَ \\
\hline $1 \pi v^{* * *}$ & $F / q^{\text {**** }}$ & $\mid f f^{* * *}$ & $19^{* * * *}$ & $9 .{ }^{* * *}$ & $r \cdot \mid \Lambda^{* * * *}$ & $\mid \Delta r^{\text {"*** }}$ & TF & دما×تنش خشكى \\
\hline $\mid \Delta \Lambda^{* * *}$ & $\Gamma / T \digamma^{* * * *}$ & $r / q^{* * *}$ & $r / V^{n s}$ & $A r^{* * * \%}$ & $r \cdot r^{* * *}$ & $19^{\mathrm{ns}}$ & r & يرايمينَح×تنش خشكى \\
\hline $9 . *$ & $1 / 4^{* * *: *}$ & $T / V^{* * *}$ & $\varepsilon / T^{* *: *}$ & $9^{* * * *}$ & $V e^{*}$ & $r q^{\mathrm{ns}}$ & TF & دما×يرايمينَگتنش خشكى \\
\hline $1 / \pi$ & $1 \cdot / r$ & $1 / 1 \pi$ & $\mu / l$ & $1 / \cdot 9$ & (I) & rt & rI. & خطا \\
\hline 19 & ir & 1. & 11 & $1 \pi / \pi$ & IT & $9 / 1$ & & ضريب تغييرات (درصد) \\
\hline
\end{tabular}

كمتر از هادرجه سانتى گراد سرعت جوانهزنى بـهميـزان

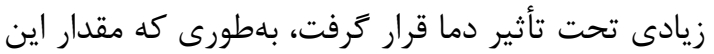
شاخص در دماهاى ب و 4 درجه سانتى

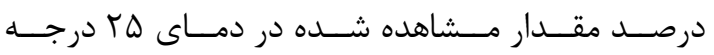

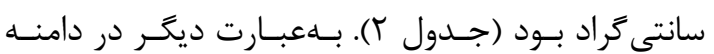

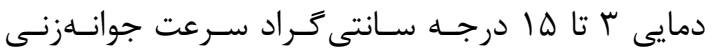

\section{سرعت جوانهزنى}

نتايج جدول تجزيه واريانس نشان داد كه كليه اثرات

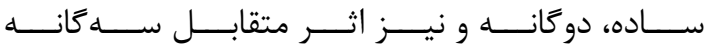

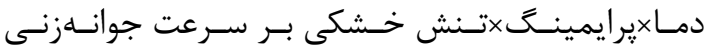
معنى دار است (جدول (). بـدون در نظـر زَــفتن سـطح

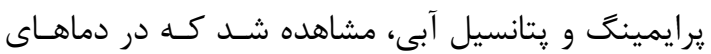


معنىدارشدن تفاوت سرعت جوانهزنى بذرهاى برايمشده

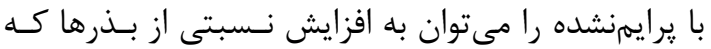

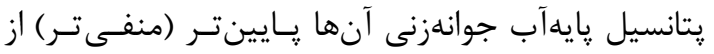

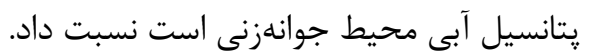
بهاطور كلى، با در نظر كرفتن روند تغييرات سرعت استى

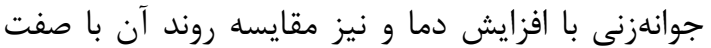

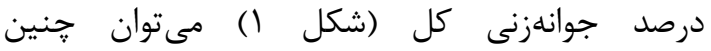
نتيجه مقايسه با درصد جوانهزنى عادى آهستهتر بوده و دماى

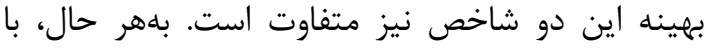
مقايسه صفات درصد جوانهزنى با سرعت جوانهزنى مىتوان كَفت كه بذرهايى كه در شدتهاى ترات تنش خشكى پايينتر سرعت جوانهزنى بالاترى دارند، درصد

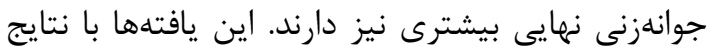

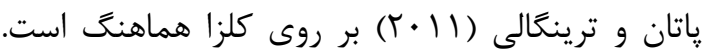

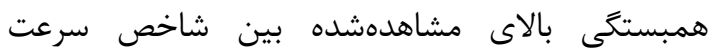

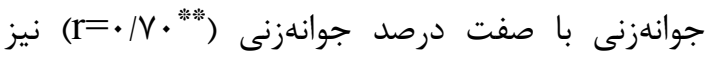
مىتواند شاهدى بر اين ادعا باشد، اين در حالى است كه رابطه بين اين شاخص با درصد جوانهزنى غيرعادى

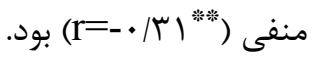

\section{ميانگين زمانى جوانهزنى (MGT)}

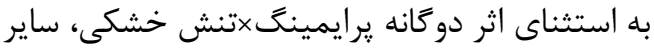
اثرات ساده و تركيبى سطوح مختلف دمايى-رطوبتى بر

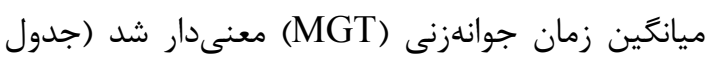

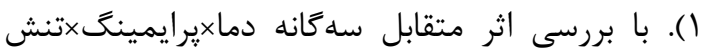
خشكى مشخص شد كه بذرهاى با سرعت جوانهزنى بالاتر MGT بايينترى داشته و در نتيجه زودتر نيز به به باني

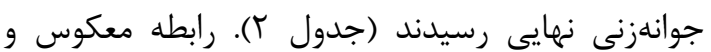

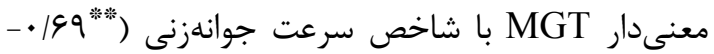

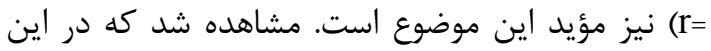
شرايط شدتهاى تنش خشكى صفر بار و r ب- بار در

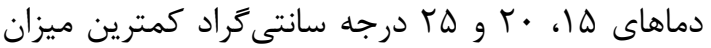

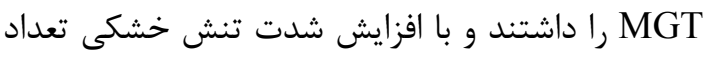

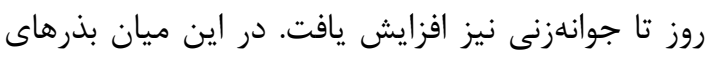

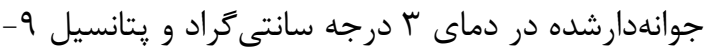
بار با ميانخين MGT تقريبى \ل روز بيشترين مقدار اين شاخص را بهخود اختصاص دادند.
بلهورت خطى افزايش يافت و شيب افزايش در بـــرهاى

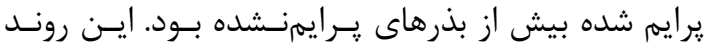

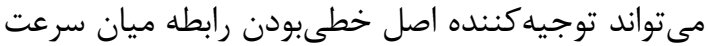

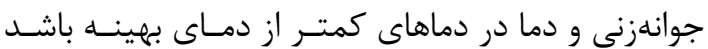

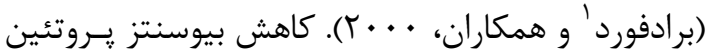

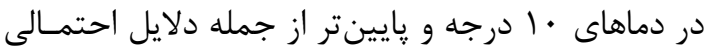
كاهش جوانهزنى كلزا در شريط تـــش سـرمايى كَزارش

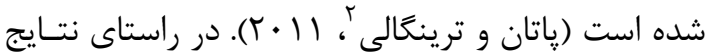

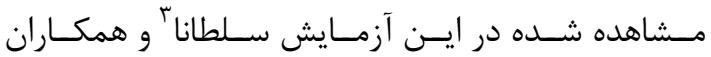

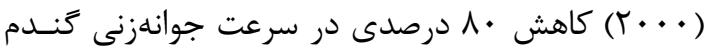

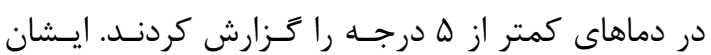

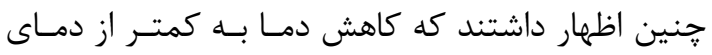

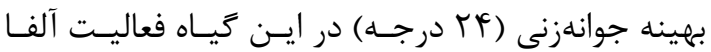

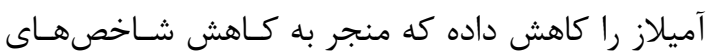

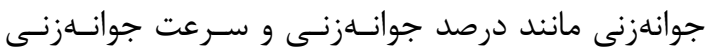
مىشود. مشابه با صفت درصد جوانهزنى و نيز مطالعات انجـام

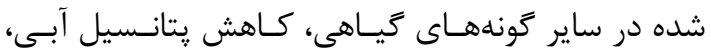

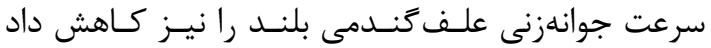

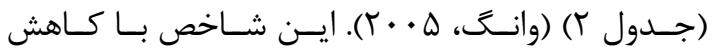

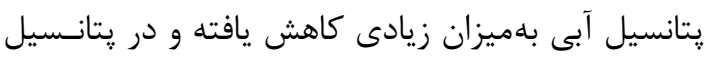

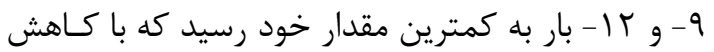
مشاهدهشه در صفات درصد جوانـهزنسى نيـز هماهنـــ

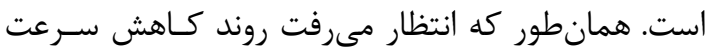

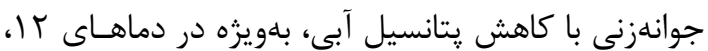

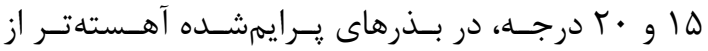

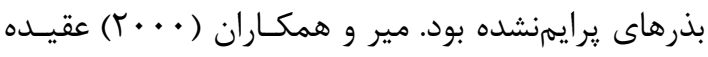

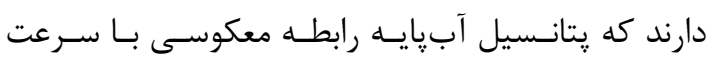
جوانهزنى دارد و تيمارها در شرايطى كه يتانسيل آبرايايه

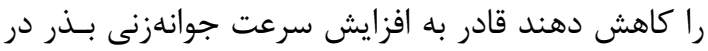

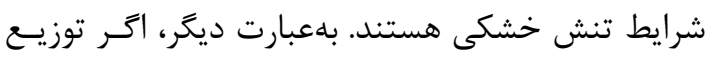

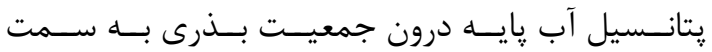

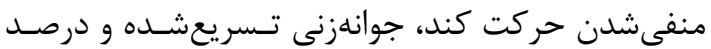

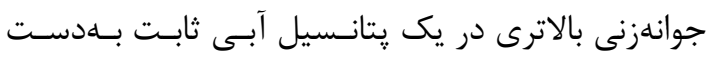

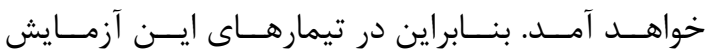

\footnotetext{
${ }^{1}$ Bradford

2 Patane and Tringali

3 Sultana
} 


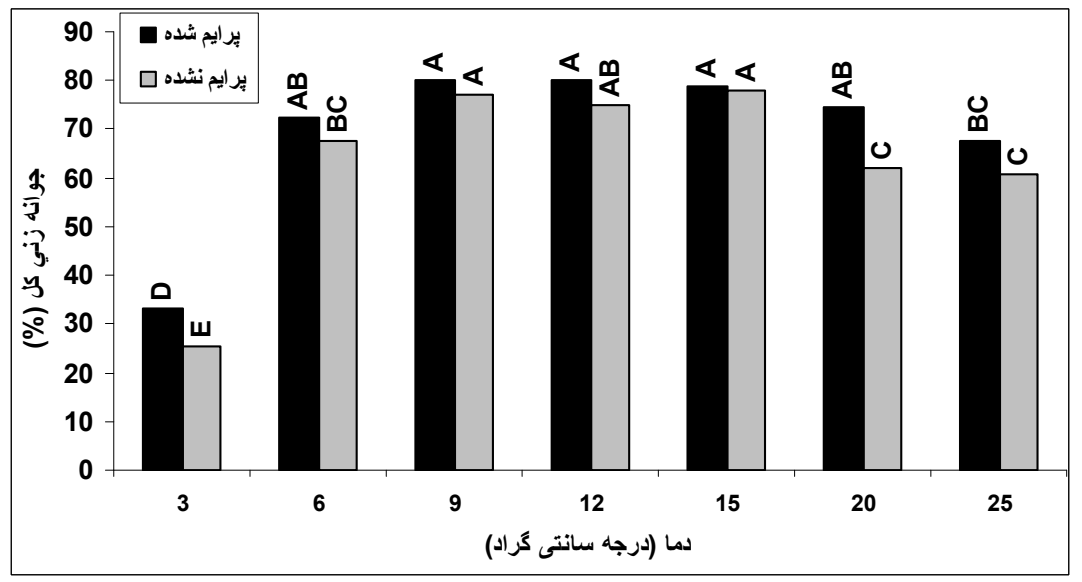

(الف)

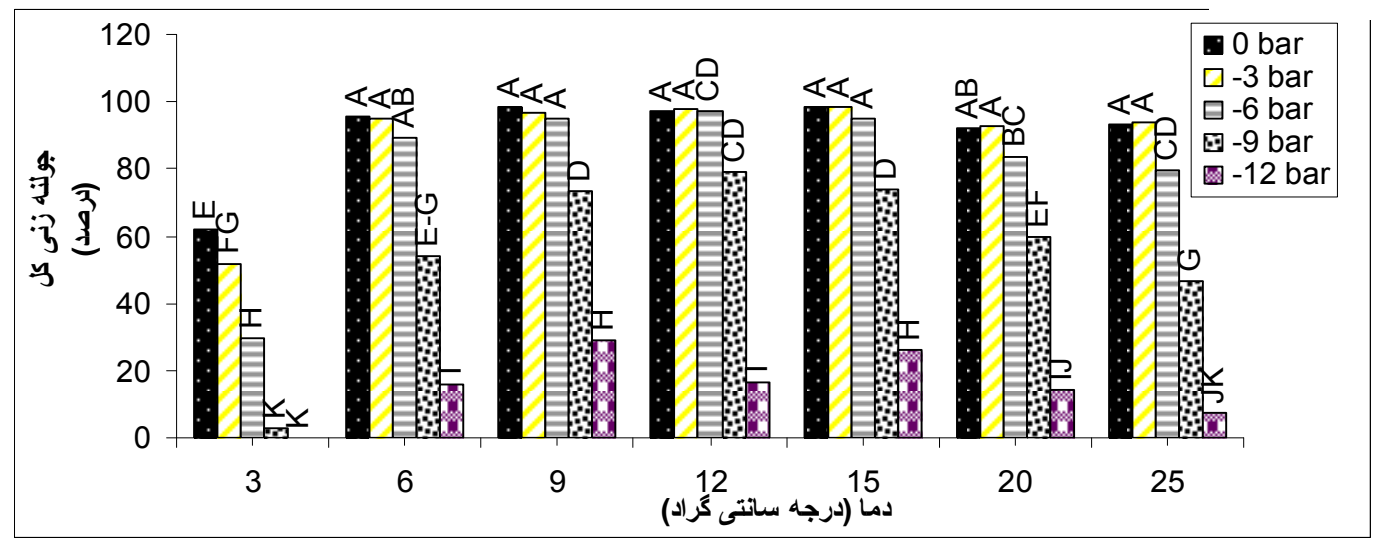

شكل ا- مقايسه ميانگَين اثرات متقابل دماءيرايمينَ (الف) و دما×تنش خشكى (ب) بر درصد جوانهزنى كل بذرهاى علف گندمى بلند، هر ستون از

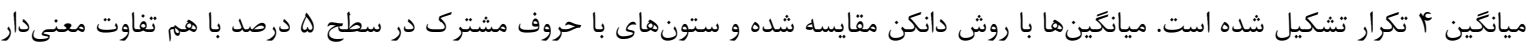

به تنش دست يافت. با ارزيابى طول زياهجه در دماهاى

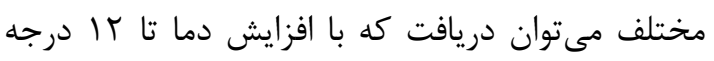
سانتى

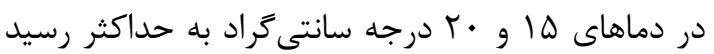

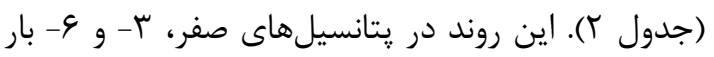
صادق بوده و در شدتهاى بالاتر تنش خشكى ( 9 (- و rا - بار) مشاهده نشد. از طرفى، بدون توجه به دما و با

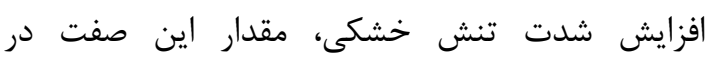
شدتهاى تنش خشكى صفر و بـ- بار تفاوت جندانى نداشته و با افزايش شدت تنش خشكى از س- به و- و و

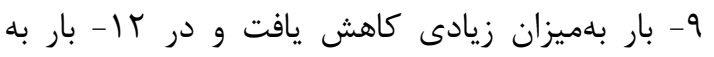
نزديك صفر رسيد. به هر حال، طول گياهجه بين بذرهاى يرايمشده و يرايمنشده نيز متفاوت بود، اين روند

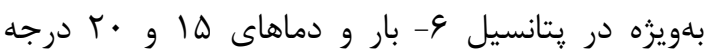

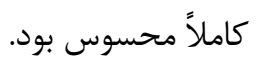

به هر حال با مقايسه اين شاخص در دماها و يتانسيلهاى مختلف مى توان مشاهده كرد كه ميانخين

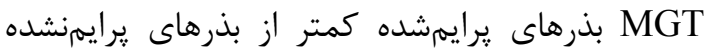

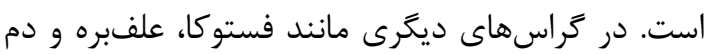
روباهى نيز رابطهاى معكوس ميان MGT و دما ززارش

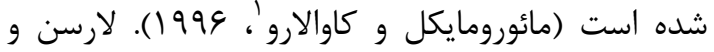

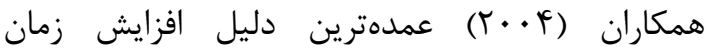
جوانهزنى با افزايش شدت تنش خشكى و كاهش دما ران به طولانى ترشدن مرحله دوم جذب آب نسبت دادهاند

\section{طول كَياهجه}

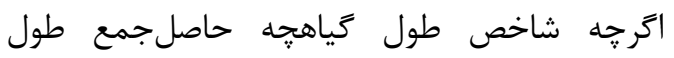
ريشهجه و ساقهجه است، اما با بررسى اين صفت مىتوان به ديد بهترى درباره واكنش رشد جوانهزنى بذر

\footnotetext{
${ }^{1}$ Mauromicale and Cavallaro
} 


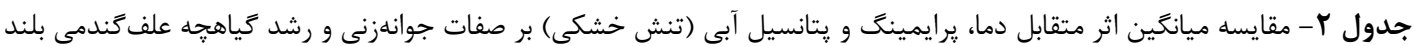

\begin{tabular}{|c|c|c|c|c|c|c|c|c|}
\hline شاخص & سيشبت طوله به & طول گياهجه & ميانگين زمان & جوانهزنى سرعت & غوانهزنى & خشكى & يرايمينَ & 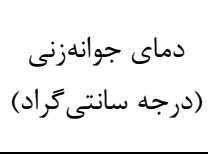 \\
\hline$\cdot / \cdot^{\mathrm{n}}$ & $\cdot /^{v}$ & $\cdot / \cdot \mathrm{s}$ & $10 / 9 V^{a-d}$ & $r / T \varphi^{v-y}$ & $G Y / /^{f-g}$ & صفر & & \\
\hline$\cdot /^{\mathrm{n}}$ & $\cdot /{ }^{v}$ & $\cdot /{ }^{\mathrm{s}}$ & $19 / \Delta \Delta^{\mathrm{a}-\mathrm{c}}$ & $1 / 19^{w-z}$ & $\Delta \Lambda / V^{f-h}$ & r & & \\
\hline$\cdot /{ }^{\mathrm{n}}$ & $\cdot / \bullet^{\mathrm{v}}$ & $\cdot /{ }^{\mathrm{s}}$ & $1 \varepsilon / V r^{\mathrm{a}-\mathrm{c}}$ & $\cdot 199^{x-z}$ & $r r / \omega^{1-n}$ & -4 & يرايم شده & \\
\hline$\cdot /^{\mathrm{n}}$ & $\cdot /{ }^{v}$ & $\cdot / \cdot \mathrm{s}$ & $|\Lambda| \cdot 4^{a}$ & $\cdot / 1^{\mathrm{yz}}$ & $r / \cdot^{r-u}$ & -9 & & \\
\hline$\cdot /{ }^{n}$ & $\cdot /{ }^{v}$ & $\cdot / \cdot \mathrm{s}$ & - &.$^{z}$ & ${ }^{\mathrm{u}}$ & -14 & & \\
\hline$\cdot /{ }^{\mathrm{n}}$ & $\cdot / \cdot^{\mathrm{v}}$ & $\cdot / \cdot \mathrm{s}$ & $|\mathrm{V} /|^{\mathrm{ab}}$ & $1 / 9 r^{w-z}$ & $\Delta r / \cdot \cdot^{g-j}$ & صفر & & r \\
\hline$\cdot /{ }^{\mathrm{n}}$ & $\cdot / v^{v}$ & $\cdot / \cdot \mathrm{s}$ & $\mid f / K^{c-e}$ & $1 / r^{w-z}$ & $F q / v^{j k}$ & r & & \\
\hline$\cdot /{ }^{\mathrm{n}}$ & $\cdot / \cdot^{\mathrm{v}}$ & $\cdot / \cdot \mathrm{s}$ & $|r / \mu|^{d-g}$ & $\cdot / V e^{x-z}$ & $r \varepsilon / \omega^{\mathrm{m}-\mathrm{o}}$ & -9 & يرايمنشده & \\
\hline$\cdot /{ }^{\mathrm{n}}$ & $\cdot / \bullet^{\mathrm{v}}$ & $\cdot / \cdot \mathrm{s}$ & $|F /| r^{c-e}$ & $\cdot / \cdot \Delta^{\mathrm{yz}}$ & $r / \cdot^{t u}$ & -9 & & \\
\hline$\cdot / \cdot^{n}$ & $\cdot / \cdot v$ & $\cdot / \cdot \mathrm{s}$ & - &.$^{\mathrm{z}}$ & $\cdot 1 \cdot^{\mathrm{u}}$ & -14 & & \\
\hline$\cdot / \vee q^{n}$ & $1 / / \wedge^{k-m}$ & $1 / \mathrm{v}^{0-\mathrm{s}}$ & $\Lambda / 1 Q^{i-r}$ & $q / r^{n-q}$ & $\Delta r / \Delta^{h-j}$ & صفر & & \\
\hline$\cdot / 99^{n}$ & $1 / \Delta 9 \mathrm{hi}$ & $r / Y)^{\mathrm{n}-\mathrm{q}}$ & $\Lambda / \& V^{i-q}$ & $\Delta / 9^{0-r}$ & $\Delta / / r^{h-j}$ & r & & \\
\hline$\cdot / \mu^{n}$ & $\Gamma / \Gamma \Lambda^{c}$ & $1 /\left.A\right|^{0-s}$ & $1 \cdot 1 \mathrm{~A}^{\mathrm{f}-\mathrm{j}}$ & $f / \Delta^{q-t}$ & $\Lambda F / \cdot^{a b}$ & -9 & يرايمشده & \\
\hline$\cdot / \cdot^{\mathrm{n}}$ & $\cdot / \cdot v$ & $\cdot / 4^{\mathrm{p}-\mathrm{s}}$ & $\mid r / 4 \varepsilon^{d g}$ & $r / T^{u-x}$ & $\Delta \varepsilon / \cdot^{g-i}$ & -9 & & \\
\hline$\cdot /{ }^{n}$ & $\cdot / \cdot^{v}$ & $\cdot / r \Delta^{r-s}$ & $1 \% / q \mu^{c-e}$ & $\cdot 119^{\mathrm{x}-\mathrm{z}}$ & $T r / V^{\mathrm{n}-\mathrm{p}}$ & -14 & & \\
\hline 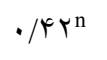 & $1 / 9 \gamma^{g}$ & $1 / 94^{0-s}$ & $q / \varepsilon r^{h-n}$ & $\Delta / r v^{p-s}$ & $V I / \cdot^{c-e}$ & صفر & & 4 \\
\hline$\cdot / r q^{n}$ & $r / \Delta)^{f}$ & $1 / \Delta r^{0-s}$ & $1 \cdot / \cdot r^{h-1}$ & $F / \Lambda r^{q-t}$ & $V \psi / A^{b-d}$ & r & & \\
\hline$\cdot / \cdot 1^{\mathrm{n}}$ & $1 / 9 . \mathrm{hi}$ & $1 / \Gamma \cdot 0-s$ & $\mid r / 9 V^{d-g}$ & $r / \Lambda \cdot{ }^{s-v}$ & $\Lambda N /{ }^{a}$ & -9 & يرايمنشده & \\
\hline$\cdot / \cdot^{\mathrm{n}}$ & $\cdot / \bullet^{v}$ & $\cdot /\left.F\right|^{q-s}$ & $|f / V|^{b-e}$ & $1 / V Y^{w-z}$ & $\Delta r / \cdot^{g-j}$ & -9 & & \\
\hline$\cdot / \cdot^{\mathrm{n}}$ & $\cdot{ }^{\mathrm{v}}$ & $\cdot / \cdot \wedge^{\mathrm{s}}$ & $9 / 9 \vee^{\mathrm{h}-1}$ & $1 / 10^{x-z}$ & $\Lambda / V^{q-u}$ & -14 & & \\
\hline$r / 9 . \mathrm{kl}$ & $\cdot / \Delta \Lambda^{s-u}$ & $r / r \Delta^{1 m}$ & $\Delta / \Lambda)^{q-y}$ & $9 / 41^{i-1}$ & $\Lambda / \cdot^{q-u}$ & صفر & & \\
\hline$\varphi / 9 \Lambda^{\mathrm{kl}}$ & $1 / \cdot r^{1-p}$ & $\Delta / 41^{\mathrm{kl}}$ & $41 \cdot 1^{\mathrm{p}-\mathrm{x}}$ & $\Lambda / V k^{\mathrm{j}-\mathrm{m}}$ & $\mid f / \Delta^{p-r}$ & - & & \\
\hline $1 / r q^{n}$ & $r / \mathscr{q f}$ & $r / \Delta \Lambda^{\mathrm{mn}}$ & $V / V)^{k-s}$ & $V / \cdot e^{r-u}$ & $G Y / D^{e-g}$ & -9 & يرايمشده & \\
\hline$r / \cdot r^{n}$ & $r / V q^{e}$ & $1 / 990-8$ & $1 \cdot|\wedge|^{\mathrm{f}-\mathrm{j}}$ & $F / \cdot r^{r-u}$ & $V \Psi / \Delta^{c d}$ & -9 & & \\
\hline$\cdot /{ }^{\mathrm{n}}$ & $\cdot /{ }^{v}$ & 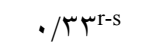 & $\mid r / \cdot \varphi^{d-g}$ & $1 / r \Lambda^{\mathrm{w}-\mathrm{z}}$ & rr/. & $-1 T$ & & \\
\hline$r / F r^{\mathrm{kl}}$ & $1 / \cdot 4^{1-0}$ & $\Delta / \cdot r^{\mathrm{k}-\mathrm{m}}$ & $q / V \varepsilon^{n-y}$ & $\Lambda / 1 k^{\mathrm{k}-\mathrm{n}}$ & $11 / \Delta^{q-t}$ & صفر & & 9 \\
\hline$\varphi /\left.f\right|^{\mathrm{kl}}$ & $1 / Y V^{j-1}$ & $\Delta / T^{\mathrm{k}-\mathrm{m}}$ & $V / / r^{1-t}$ & $\mathrm{~V} / \cdot \mathrm{r}^{\mathrm{m}-\mathrm{p}}$ & $1 \Psi / \omega^{p-s}$ & r & & \\
\hline$\cdot / F \gamma^{n}$ & $r / \cdot^{d}$ & $r / r q^{n-p}$ & $q / \vee \Delta^{m-h}$ & $\Delta / \Delta \xi^{p-s}$ & $V F / \cdot^{c d}$ & -9 & يرايمنشده & \\
\hline$\cdot / \cdot^{\mathrm{n}}$ & $\cdot / \cdot^{v}$ & $\cdot / \wedge \wedge^{0-\mathrm{s}}$ & $11 / 1^{e-g}$ & $r / \mid q^{1-w}$ & $V Y / \cdot^{c-e}$ & -9 & & \\
\hline$\cdot / \cdot^{n}$ & $\cdot /{ }^{v}$ & $\cdot / r V^{s}$ & $\mid r / \& 9^{d-f}$ & $1 / \cdot e^{x-z}$ & $r \varepsilon / D^{\mathrm{m}-\mathrm{o}}$ & -14 & & \\
\hline $9 / \Gamma \Lambda^{h}$ & $\cdot / q^{\text {tu }}$ & $1 \cdot 1 \cdot^{h}$ & $r / r V^{X-Z}$ & IV/Trcd & $r / b^{r-u}$ & صفر & & \\
\hline $\begin{array}{l}1 \mathrm{H}^{\mathrm{g}} \\
11\end{array}$ & $1 / \cdot^{1-p}$ & $11 / \Delta 9 g$ & $r / v q^{v-z}$ & $\mid f / 9^{e f}$ & $r / \Delta^{s-u}$ & r & & \\
\hline$r / V \cdot k l$ & $r / r q^{\mathrm{f}}$ & $\Delta / V \cdot k l$ & $\Delta / V \Lambda^{q-y}$ & $1 \cdot / r^{h-j}$ & $r y / \cdot{ }^{l m}$ & -9 & يرايمشده & \\
\hline$\cdot 1 \cdot 9^{n}$ & $r / \partial Y^{c}$ & $r / \cdot^{n-r}$ & $9 / 19^{h-o}$ & $\Delta / r \omega^{\mathrm{p}-\mathrm{s}}$ & $\vee q / \cdot^{a-c}$ & -9 & & \\
\hline$\cdot / \cdot^{\mathrm{n}}$ & $\cdot /{ }^{\mathrm{v}}$ & $\cdot / 1 \cdot \mathrm{s}$ & $1 \cdot 19^{\mathrm{f}-\mathrm{i}}$ & $1 / / v^{w-z}$ & $r T / N^{n-p}$ & -14 & & \\
\hline$V / \Delta \Lambda^{\mathrm{hi}}$ & $\cdot / 9)^{\mathrm{s}-\mathrm{u}}$ & $9 / / r^{\mathrm{hi}}$ & $r / \Delta V^{t-z}$ & $11 / \wedge^{g h}$ & $\mid f / \cdot^{p-r}$ & صفر & & ir \\
\hline$V / 9)^{i}$ & $\cdot / 9 V^{\mathrm{m}-\mathrm{q}}$ & $\Lambda / \mathcal{F} \Delta^{\mathrm{hi}}$ & 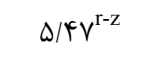 & $1 \cdot 1 r^{g h}$ & $V / \omega^{p-r}$ & r & & \\
\hline$r / F)^{l m}$ & $1 / 91 \mathrm{hi}$ & $\Delta / \cdot v^{k-m}$ & $q / \wedge 9^{m-u}$ & $V / \Lambda^{1-n}$ & $r q / \Delta^{1-n}$ & -9 & يرايمنشده & \\
\hline$\cdot / \cdot^{\mathrm{n}}$ & $\cdot /{ }^{\mathrm{v}}$ & $1 / 1 \mathrm{~A}^{\mathrm{o}-\mathrm{s}}$ & $1 \cdot 1 \Delta \Delta^{\mathrm{g}-\mathrm{k}}$ & $F / / r^{r-i}$ & $V \varepsilon / .^{b-d}$ & -9 & & \\
\hline$\cdot /{ }^{\mathrm{n}}$ & $\cdot /{ }^{v}$ & $\cdot / /^{\mathrm{s}}$ & $1 \cdot 19 r^{\mathrm{g}-\mathrm{k}}$ & $\cdot 1 \Delta \Delta^{\mathrm{x}-\mathrm{z}}$ & $1.1 .^{q-u}$ & -14 & & \\
\hline
\end{tabular}


جدول r (ادامه)

\begin{tabular}{|c|c|c|c|c|c|c|c|c|}
\hline شياخص & 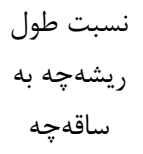 & (سانتى متر) & ميانگين زمان & 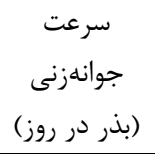 & غوانهزنى & خشكى & يرايمينَ & (درجه سانتى جوانهزادى) \\
\hline$I V / V F^{b c}$ & $\cdot / V \varepsilon^{\mathrm{p}-\mathrm{t}}$ & $|N| \cdot V^{\mathrm{de}}$ & $r / \Delta H^{Z}$ & $r r / T K^{b}$ & $1 / 0^{t u}$ & صفر & & \\
\hline$I V / r \Delta^{b c}$ & $1 / \cdot 1^{1-p}$ & $1 V / \wedge 9^{d e}$ & $r / I V^{x-z}$ & $\mid N / \mathcal{F}^{\mathrm{c}}$ & $1 / 0^{\text {tu }}$ & r- & & \\
\hline$\varepsilon / q^{\mathrm{ij}}$ & $1 / 99^{\mathrm{hi}}$ & $9 / 91^{h}$ & $p / q^{t-z}$ & $\mid r / q^{f g}$ & $r \wedge / \Delta^{\mathrm{mn}}$ & -9 & يرايمشده & \\
\hline$\cdot 1 \cdot \Delta^{n}$ & $\Gamma / q^{c}$ & $r / 4 \varepsilon^{\text {no }}$ & $\varepsilon / 4 \varepsilon^{0-w}$ & $V / / \varepsilon^{m-p}$ & $V \Psi / Q^{c d}$ & -9 & & \\
\hline$\cdot 1 \cdot^{\mathrm{n}}$ & $\cdot \cdot^{\mathrm{v}}$ & $\cdot 11 \cdot^{\mathrm{s}}$ & $\Lambda / \|^{\mathrm{i}-\mathrm{r}}$ & $1 / \Lambda \cdot{ }^{w-z}$ & $r \Delta / q^{\mathrm{m}-\mathrm{o}}$ & $-1 T$ & & \\
\hline $\mid q / \varepsilon Y^{e f}$ & $\cdot 194^{r-u}$ & $1 \varepsilon / \Delta \Delta^{\mathrm{ef}}$ & $F / \Delta \mu^{t-z}$ & $\mid r / \varepsilon \Delta \mathrm{fg}^{\mathrm{fg}}$ & $\Lambda / \Lambda^{q-u}$ & صفر & & 10 \\
\hline $\mid r / \Lambda \cdot{ }^{f}$ & $\cdot / V r^{q-u}$ & $1 \Delta / r Y^{f}$ & $F / T)^{t-z}$ & $1 \% / \varepsilon \Delta^{f g}$ & $v / \omega^{q-u}$ & r & & \\
\hline$\Delta / \Gamma \Lambda^{\mathrm{jk}}$ & $1 / r \cdot{ }^{k-m}$ & $V / q)^{i j}$ & $\Delta / \Delta r^{r-z}$ & $9 / 9 r^{i-k}$ & $\mathrm{rV} /{ }^{\mathrm{mn}}$ & -9 & يرايمنشده & \\
\hline$\cdot / \cdot r^{n}$ & $9 / 1 f^{b}$ & $1 / \Delta r^{0-s}$ & $V / q^{\mathrm{j} j-\mathrm{r}}$ & $\Delta / \mathcal{A} T^{p-s}$ & $V / / b^{c-e}$ & -9 & & \\
\hline$\cdot 1{ }^{n}$ & $\cdot / \cdot^{\mathrm{v}}$ & $\cdot 11 \cdot{ }^{\mathrm{s}}$ & $\Lambda / \Lambda \Lambda^{i-p}$ & $1 / \wedge \cdot{ }^{w-z}$ & $\mathrm{rV} / \cdot^{\mathrm{mn}}$ & $-1 T$ & & \\
\hline $19 / \Lambda V^{a}$ & $\cdot|9|^{\mathrm{s}-\mathrm{u}}$ & $r y / / r^{a}$ & $r / r q^{z}$ & $r \Delta / \Lambda \cdot{ }^{a}$ & $r / \Delta^{r-u}$ & صفر & & \\
\hline$\left.|N| 9\right|^{\mathrm{ab}}$ & $\cdot / 9 \mathrm{v}^{\mathrm{m}-\mathrm{q}}$ & $r \cdot / \mu r^{a-c}$ & $r / 9 \Delta^{z}$ & rr/א & $\Delta / r^{r-u}$ & r & & \\
\hline$\Delta / \cdot \Delta^{\mathrm{j}-1}$ & $1 / 4 T^{\mathrm{i}-\mathrm{k}}$ & $11 / 9 r^{g}$ & $\mu / \cdot \wedge^{x-z}$ & $\mid V / F Y^{c d}$ & $\Delta r / \cdot^{g-j}$ & -9 & يرايمشده & \\
\hline$\cdot 1 \cdot 4^{n}$ & $8 / 09^{a}$ & $r / T r^{n-q}$ & $\Delta / 11^{r-z}$ & $\Lambda / V 9^{j-m}$ & $q N /{ }^{d-f}$ & -9 & & \\
\hline$\cdot 1 \cdot^{\mathrm{n}}$ & $\cdot /^{\mathrm{v}}$ & $\cdot 11 \cdot{ }^{\mathrm{s}}$ & $\Delta / q Y^{p-x}$ & $1 / 4 \Lambda^{\mathrm{w}-\mathrm{z}}$ & $1 \varepsilon 10^{0-q}$ & $-1 T$ & & \\
\hline $\mid q / \pi .^{\mathrm{cd}}$ & $\cdot|\Delta|^{t u}$ & $19 / r \Delta^{b-d}$ & $F / \Delta \Delta^{t-z}$ & $\mid c / \Delta \Lambda^{\mathrm{cd}}$ & $r / \omega^{s-u}$ & صفر & & $r \cdot$ \\
\hline $\mid \Delta / 4 q^{\mathrm{de}}$ & $\cdot \mid \Lambda \mathrm{r}^{\mathrm{O}-\mathrm{s}}$ & $19 / q^{b-d}$ & $r / \Lambda \Lambda^{u-z}$ & $\mid V / Q r^{c d}$ & $\Lambda / \Delta^{q-u}$ & r & & \\
\hline $1 / r \cdot{ }^{n}$ & $1 / \Delta r^{O-s}$ & $q / q^{j \mathrm{k}}$ & $\varphi / q v^{s-z}$ & $1 \cdot(9)^{\mathrm{hi}}$ & $\Delta q / \cdot^{f-h}$ & -9 & يرايمنشده & \\
\hline$\cdot 1{ }^{n}$ & $\cdot /^{\mathrm{v}}$ & $\cdot / \wedge v^{0-s}$ & $\Delta / \mathcal{F q}^{r-z}$ & $\Delta / 9)^{0-\mathrm{r}}$ & $\mathrm{Fq} / \mathrm{\cdot}^{\mathrm{h}-\mathrm{j}}$ & -9 & & \\
\hline$\cdot 10^{n}$ & $\cdot 1^{\mathrm{v}}$ & $\cdot / 1 \cdot{ }^{\mathrm{s}}$ & 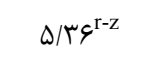 & $1 / r^{W-z}$ & $11 / 0^{0-t}$ & $-1 T$ & & \\
\hline $19 / 99^{b-d}$ & $\cdot / \& q^{\text {tu }}$ & $1 / / 9 r^{\mathrm{cd}}$ & $r / \Lambda \Lambda^{z}$ & $r V / \cdot r^{\mathrm{a}}$ & $V / T^{q-u}$ & صفر & & \\
\hline$r \cdot / \mu^{\mathrm{a}}$ & $\cdot / 19^{0-r}$ & $r \mid / 9 r^{\mathrm{a}}$ & $r / \Delta r^{z}$ & $r r / a r^{b}$ & $\Delta / \omega^{\mathrm{r}-\mathrm{u}}$ & r & & \\
\hline $1 / \wedge q^{\mathrm{mn}}$ & $1 / V k^{0-r}$ & $\Lambda / 9 \cdot \mathrm{hi}$ & $r / \cdot v^{x-z}$ & $\mid \Delta / \cdot 1^{\text {ef }}$ & $G r / 0^{e-g}$ & -9 & يرايمشده & \\
\hline$\cdot 10^{\mathrm{n}}$ & $\cdot /^{\mathrm{v}}$ & $r / F \Delta^{\text {no }}$ & $r / v v^{s-z}$ & $V(\Lambda)^{1-0}$ & $\Delta \Delta / \cdot{ }^{g-j}$ & -9 & & \\
\hline$\cdot 1 \cdot^{\mathrm{n}}$ & $\cdot /^{\mathrm{v}}$ & $\cdot / 1 \cdot{ }^{\mathrm{s}}$ & $F / \Lambda)^{s-z}$ & $1 / \cdot 0^{x-z}$ & $q / \cdot^{q-u}$ & -14 & & \\
\hline$|N /|^{b}$ & $\cdot / \& \Delta^{u}$ & $\Gamma \mid / \mu^{\mathrm{a}}$ & $r / V)^{\mathrm{yz}}$ & $r Y / \Delta F^{b}$ & $\Delta /{ }^{\mathrm{r}-\mathrm{u}}$ & صفر & & $r \Delta$ \\
\hline $\mid V / q V^{b c}$ & $\cdot(9)^{\mathrm{n}-\mathrm{q}}$ & $r \cdot 19 \Lambda^{\mathrm{ab}}$ & $r / \cdot \Delta^{x-z}$ & $1 \Lambda / V \varphi^{c}$ & $\Delta / \Gamma^{r-u}$ & r- & & \\
\hline$r / r v^{l m}$ & $1 / \Delta V^{\mathrm{hi}}$ & $q / \vee q^{h}$ & $r / F^{W-Z}$ & $19 / 1 V^{\mathrm{de}}$ & $f \Delta / \Delta^{i-k}$ & -9 & يرايمنشده & \\
\hline$\cdot 1 \cdot^{\mathrm{n}}$ & $\cdot \cdot^{\mathrm{v}}$ & $\cdot 11 \cdot{ }^{\mathrm{s}}$ & $\varepsilon / \wedge 8^{\mathrm{m}-\mathrm{v}}$ & $\Delta / f)^{p-s}$ & 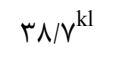 & -9 & & \\
\hline$\cdot 1{ }^{\mathrm{n}}$ & $\cdot \cdot^{\mathrm{v}}$ & $\cdot / 1 \cdot{ }^{\mathrm{s}}$ & $9 / 9 \Lambda^{h-1}$ & $\cdot / f^{x-z}$ & $r \Delta^{r-u}$ & $-1 T$ & & \\
\hline
\end{tabular}

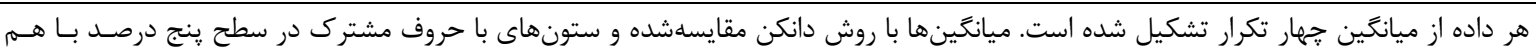
تفاوت معنى دار ندارند.

ساده و جندگًانه مطالعه شده نيز معنى دار شدند (جدول

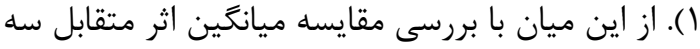

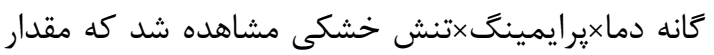

نسبت طول ريشه جه به ساقه

بين تيمارهاى مختلف از نظر نسبت طول ريشه ساقهجه نيز تفاوت معنىدار مشاهده شد و تمامى اثرات 
ساقهجه قوى وابسته است. نتايج ضرايب همبستكى نيز اين موضوع را تأييد نمود. ميزان همبستخى مشاهدهشده

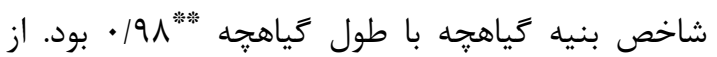
طرفى همبستكى اين شاخص با درصد بذرهاى با جوانه

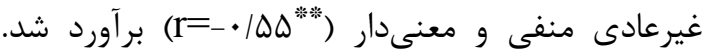
بلهبارت ديخر مىتوان كفت كه بذرهاى با جوانهزنى غيرعادى (بذرهايى كه ريشهجه و ساقهجه ناقص دارند) شاخص بنيه يايينى نيز دارند.

\section{نتيجه}

نتايج بررسى صفات جوانهزنى نشان داد كه تيمارهاى يتانسيل آبى و دما شاخصهاى جوانهزنى (از جمله درصد جوانهزنى، سرعت جوانهزنى، طول ريشه گه و و.....)

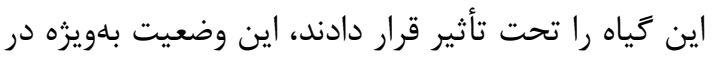

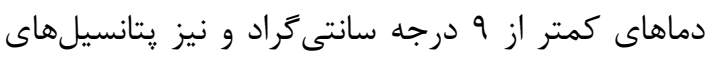

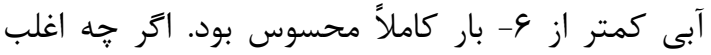

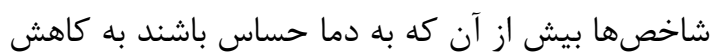

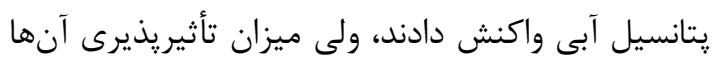

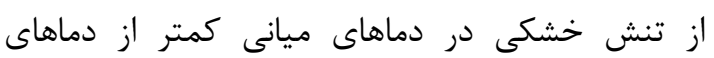

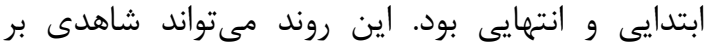
افزايش مقاومت به تنشهاى خشكى شديدتر در دماهاى

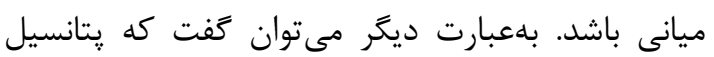

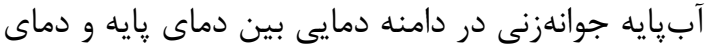
بهينه كاهش مىيابد. از طرف ديكر، در اغلب صفات اثر دابن

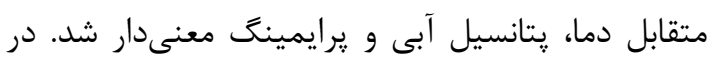

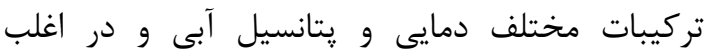

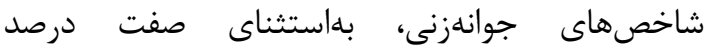

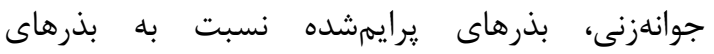

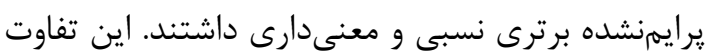
بلويزه در يتانسيل هاى آبى بالا (صفر و ــــ بار) و و دماهاى

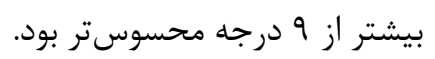

بهرحال، با در نظر گرفتن ميانگين صفاتى مانند

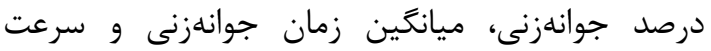

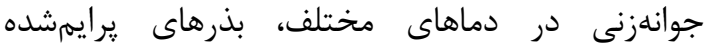

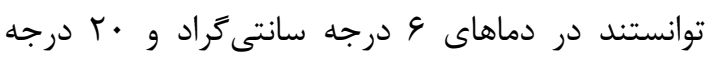
سانتى

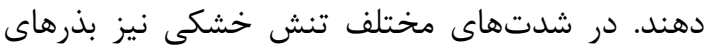

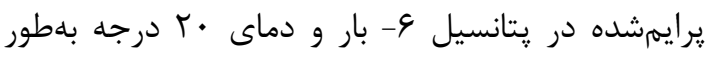

اين شاخص در دماى ץ درجه سانتى

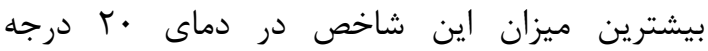
سانتى شاهدى بر افزايش توازن رشد كياهجه به نفع ريشه

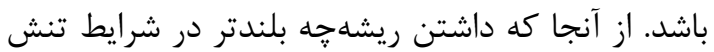
يك ويزگى مطلوب مىباشد، مىتوان كفت كه در شرايط

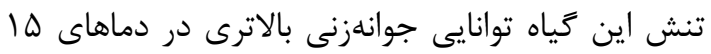

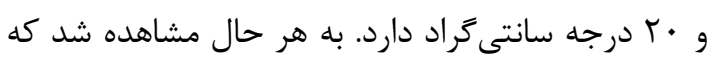
بر خلاف صفاتى مانند درصد جوانهزنى و سرعت الته جوانهزنى، نسبت طول ريشهجه به ساقهجه با افزايش

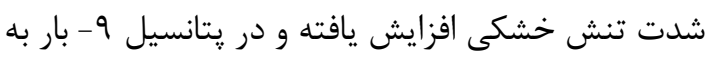
حداكثر رسيد. اين مىتواند دليلى ديخر در افزايش سازگارى به تنش خشكى با افزايش شدت تنش باشد.

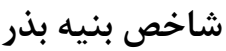

شاخص بنيه بذر بهعنوان تابعى از طول كياهجه و بذر درصد جوانهزنى نيز بهميزان معنىدارى تحت تأثير باني

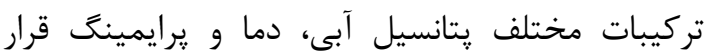
كرفت (جدول (). در اين صفت مشاهده شد كه بذرهاى

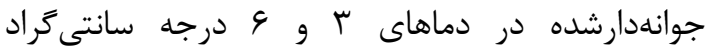

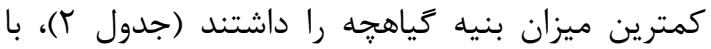

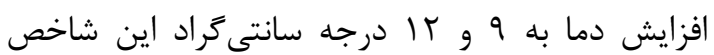
افزايشيافته، در ها درجه سانتى كراد به حداكثر رسيده

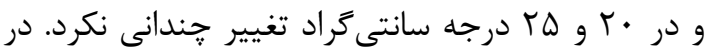

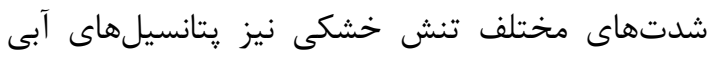
صفر و بـ- بار بيشترين ميزان شاخص بنيه را داشتند،

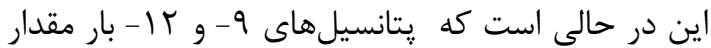

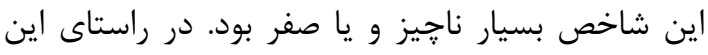

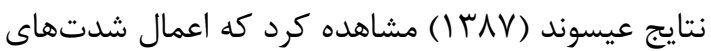
تنشهاى خشكى با קتانسيلهاى ف- و • •ا- بار در علفكندمى بلند سبب كاهش سرعت جوانهزنى، بنيه كياهجه، وزن كياهجه، طول ساقه شد، در حالى كه متوسط زمان جوانهزنى و نسبت ريشهجه به ساقه קه را افزايش داد.

با مقايسه شاخصهاى درصد جوانهزنى و طول

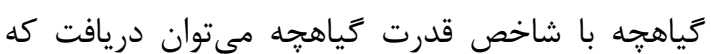
اين شاخص بيش از آن كه به درصد بذرهاى جوانهزده وابسته باشد به توانايى گياهجه براى توليد ريشهجه و 


$$
\text { نسبى جوانهزنى بهترى نسبت به بذرهاى :رايمنشده }
$$

Abdual-baki, A.A., and Anderson, J.D. 1973. Relationship between decarboxylation of glutamic acid and vigour in soybean seed. Crop Science, 13(2): 227-232.

Agrawal, R.L. 1991. Seed Technology. Oxford and IBH Publishing, 658 p.

At Karaki, G.N. 1998. Response of wheat and barley during germination to seed osmopriming at different water potential. Journal of Agronomy and Crop Science, 181(4):229-235.

At Mudarsi, M.A., and Jutzi, S.C. 1999. The influence of fertilizer-based seed priming treatments on emergence and seedling growth of Sorghum bicolor and Pennisetum glaucum in pot trials under greenhouse conditions. Journal of Agronomy and Crop Science, 182(2): 135-142.

Bradford, F., Chen, F., and Cooley, M.B. 2000. Gene expression prior to radicle emergence in imbibed tomato seeds. In Black, M., Bradford, K. J. and Vasquez-Ramos, J (eds), Seed biology: Advances and Applications. CABI, Wallingford, UK. pp: 231-251.

Bray, C.M. 1995. Biochemical processes during the osmopriming of seeds. Seed Development and Germination. New York: Marcel Dekker, pp:767-789.

Burgass, R., and Powell, A. 1984. Evidence for repair processes in the invigoration of seeds by hydration. Annals of Botany, 53(5): 753-757.

Dell'Aquila, A. and Tritto, V. 1990. Ageing and osmotic priming in wheat seeds: effects upon certain components of seed quality. Annals of Botany, 65(1): 21-26.

Dell'Aquila, A., and Bewley, J.D. 1989. Protein synthesis in the axes of polyethyleneglycol-Treated pea seed and during subsequent germination. Journal of Experimental Botany, 40(9): 10011007.

Demir, I., and Mavi, K. 2004. The effect of priming on seedling emergence of differentially matured watermelon (Citrullus lanatus (Thunb.) Matsunm and Nakai) seeds. Scientia Horticulturae, 102(4): 467-473.

Ellis, R.A., and Roberts, E.H. 1981. The quantification of ageing and survival in orthodox seeds. Seed Science and Technology, 9: 373-409.

Finch-Savage, W.E., Dent, K.C., and Clark, L.J. 2004. Soak condition and temperature following sowing influence the response of maize (Zea mays L.) seeds to on-farm priming (pre-sowing seed soak). Field Crops Research, 90(2): 361-374. 
Hardegree, S.P., and Van Vactor, S.S. 2000. Germination and emergence of primed grass seeds under field and stimulated-field temperature regimes. Annals of Botany, 85(3): 379-390.

Hardegree, S.P., Jones, T.A., and Van Vactor, S.S. 2002. Variability of thermal response of primed and non-primed seeds of Squirreltail [Elymus elymoides (Raf.) Swezey and Elymus multisetus (J.G. Smith) M.E. Jones]. Annals of Botany, 89(3): 311-319.

Harris, D., Pathan, A.K., Gothkar, P., Joshi, A., Chivasa, W., and Nyamudeza, A. 2001. On-farm seed priming: using participatory methods to revive and refine key technology. Agricultural Systems, 69(1): 151-164.

ISTA, 2010. Rules for Seed Testing. International Seed Testing Association, Zurich, Switzerland.

Kaur, S., Gupta, A.K., and Kaur, N. 1998. Gibberellic acid and kinetin partially reverse the effect of water stress on germination and seedling growth in chickpea. Plant Growth Regulation, 25(1): 29-33.

Larsen, S.U., Bailly, C., Come, D., and Corbineau, F. 2004. Use of the hydrothermal time model to analyse interacting effects of water and temperature on germination of three grass species. Seed Science Research, 14(1): 35-50.

Mauromicale, G., and Cavallaro V. 1996. Effects of seed osmopriming on germination of three herbage grasses at low temperatures. Seed Science and Technology, 24(2): 331- 338.

Meyer, S.E., Debaene-Gill,S.B. , and Allen, P.S. 2000.Using hydrothermal time concepts to model seed germination response to temperature, dormancy loss, and priming effects in Elymus elymoides. Seed Science Research, 10(3): 213-223.

Michel. B.E., and Kaufman, M.R. 1973. The osmotic potential of polyethylene glycol 6000. Plant Physiology, 51(5): 914-916.

Patane, C., and Tringali, S. 2011. Hydrotime analysis of Ethiopian mustard (Brassica carinata A. Braun) seed germination under different temperatures. Journal of Agronomy and Crop Science, 197(2): 94-102.

Posmyk, M.M., Corbineau, F., Vinel, D., Bailly, Ch., and Come, D. 2001. Osmoconditioning reduces physiological and biochemical damage induced by chilling in soybean seeds. Physiological Plantarum, 111(4): 473-482.

Ruan, S., Xue, Q., and K. Tylkowska, 2002. Effects of seed priming on emergence and health of rice (Oryza sativa L.) seeds. Seed Science and Technology, 30(1): 61-67

Soeda Y, Konings, C.J.M., Vorst, O., Van Houwelingen, M.M.L., Stoopen, G.M.C., Maliepaard, A., Kodde, J., Bino, R.J., Groot, S.P., and van der Geest, A.H.M. 2005. Gene expression programs during Brassica oleracea seed maturation, osmopriming, and germination are indicators of progression of the germination process and the stress tolerance level. Plant Physiology, 137(1): 354-368.

Sultana, N., Ikeda, T., and Mitusi, T. 2000. GA3 and proline promote germination of wheat seed by stimulating $\alpha$-amylase at unfavorable temperatures. Plant Production Science, 3(3): 232-237.

Wang, R., 2005. Modeling seed germination and seedling emergence in winterfat (Krascheninnikovia lanata (Pursh) A.D.J. Meeuse and Smit): Physiological mechanisms and ecological revelance. Ph.D thesis, University of Saskatchewan, 197 p. 


\title{
Increasing Seed Germination Efficiency of Tall Wheat Grass (Agropyron elongatum (Host.) P. Beauv) at Low Temperature and Drought Stress Conditions Using Urea Osmopriming
}

\author{
Ali Moradi ${ }^{1, ~ *}$, Farzad Sharif Zadeh ${ }^{2}$, Reza Tavakkol Afshari ${ }^{3}$, Reza Maali Amiri ${ }^{4}$ \\ ${ }^{1}$ Assistant Professor, Department of Agronomy and Plant Breeding, Yasouj University, Yasouj, \\ Iran \\ ${ }^{2,3,4}$ Associate Professor, Professor and Associate Professor, Department of Agronomy and Plant \\ Breeding, College of Agriculture and Natural Resources, University of Tehran, Tehran, Iran \\ *Corresponding author, E-mail address: amoradi@yu.ac.ir
}

(Received: 2014.02.26 - Accepted: 2014.12.30)

\begin{abstract}
Seed priming is one of the most important techniques used to improve seed germination under biotic and abiotic stresses. For this purpose, germination and seedling growth characteristics of primed seeds of Tall wheat grass (Agropyron elongatum (Host.) P. Beauv) were evaluated under drought and low temperature condition. A factorial experiment was conducted on the basis of randomized completely block design with three factors with four replications. The experimental factors were priming with two levels including urea primed (using urea -4 bar at $10{ }^{\circ} \mathrm{C}$ for $36 \mathrm{~h}$ ) and non-primed seeds; germination temperatures, including $3,6,9,12,15,20$ and $25^{\circ} \mathrm{C}$; and osmotic potential including zero (distilled water), $-3,-6,-9$, and -12 bars (applied by polyethylene glycol 6000). Increasing trend have been observed for all germination indices, except mean germination time, with increasing temperature from 3 to $25^{\circ} \mathrm{C}$ and seeds revealed the greatest sensitivity to temperatures below $9{ }^{\circ} \mathrm{C}$. However, this trend was reversed with increasing drought stress, the seeds sensitivity to drought stress started from the potential of -6 bar and reached to maximum in -12 bar. However, primed seeds compared to non-primed seeds have demonstrated better germination under both drought and low temperature stresses. The results of this study showed that the highest seedling vigor index and germination rates achieved in the temperature range of $20-25^{\circ} \mathrm{C}$ and water potential of zero to -3 bar.
\end{abstract}

Keywords: Seed osmoprimingWater potential, Low temperature, Tall wheatgrass 